\title{
Body of the Pancreas
}

National Cancer Institute

\section{Source}

National Cancer Institute. Body of the Pancreas. NCI Thesaurus. Code C12270.

The part of the pancreas from the point where it crosses the portal vein to the point where it enters the lienorenal ligament. 